Running Head: IMPLICIT THEORIES OF MENTAL TOUGHNESS

\title{
Implicit Theories of Mental Toughness: Relations with Cognitive, Motivational and Behavioral Correlates
}

Daniel F. Gucciardi ${ }^{1}$, Ben Jackson ${ }^{2}$, Ken Hodge $^{3}$, David R. Anthony ${ }^{2}$, and Lauren E. Brooke ${ }^{1}$

${ }^{1}$ School of Physiotherapy and Exercise Science, Curtin University

${ }^{2}$ School of Sport Science, Exercise and Health, The University of Western Australia

${ }^{3}$ School of Physical Education, Sport and Exercise Sciences, University of Otago

Corresponding author: Daniel Gucciardi, School of Physiotherapy and Exercise Science, Curtin University, GPO Box U1987, Perth, Australia, 6845. Phone: +61 89266 3653, Fax: +61 89266 3699, Email: daniel.f.gucciardi@ gmail.com

Submitted for publication: March $11^{\text {th }} 2014$

Revised manuscript submitted: April $24^{\text {th }} 2014$

Manuscript accepted for publication in Sport, Exercise and Performance Psychology: May $21^{\text {st }} 2014$ 


\begin{abstract}
People differ in their implicit theories about mental toughness, that is, whether they believe this quality is immutable (entity theorists) or changeable (incremental theorists). The aim of this study was to explore whether peoples' implicit theories of mental toughness are related to cognitive, motivational, and behavioral variables considered as hallmarks of this personal quality. We conducted three studies with participants from different achievement contexts: 444 undergraduate students aged 17 to 26 years $(M=19.25) ; 395$ employees aged 25 to 79 years $(M=48.78)$; and 230 adolescent athletes aged 11 to 17 years $(M=14.98)$. Students completed a measure of implicit theories of mental toughness, fear of failure, and perceived stress. Employees completed a measure of implicit theories and were rated on performance and creativity by their supervisor. Athletes completed a measure of implicit theories of mental toughness, resilience, and thriving. Across all three samples, cluster analyses supported the existence of an incremental theory (high incremental theory, low entity theory) alongside an ambivalent group (moderate scores on both theory theories). These clusters differed on fear of failure, stress, performance, creativity, resilience and thriving consistent with theoretical expectations. The current findings suggest that people's implicit theories of mental toughness may have important implications for understanding cognitive, motivational and behavioral correlates considered hallmarks of this psychological concept.
\end{abstract}

Keywords: cluster analysis; mentally tough; resilient; self-theories 


\section{Implicit Theories of Mental Toughness: Relations with Cognitive, Motivational and Behavioral Correlates}

Is personality a product of nature or nurture? Is intelligence something that people can change or develop? Questions such as these have garnered substantial empirical interest from scholars over the past few decades (e.g., Davids \& Baker, 2007; Roberts \& Mroczek, 2008). In most instances, one could locate scientific evidence to support either an affirmative or negative response to such questions ${ }^{1}$. An alternative, yet equally interesting perspective is to consider people's lay beliefs regarding the nature of these personal attributes. A considerable body of research has revealed that people's responses to these questions about the nature of human attributes can have a significant influence on their behavior across a variety of contexts (e.g., Burnette, O’Boyle, VanEpps, Pollack, \& Finkel, 2013; Yeager, Miu, Powers, \& Dweck, 2013) - these layperson responses are referred to as 'implicit theories' (Dweck \& Leggett, 1988). In this study, we extended this body of knowledge on implicit theories to a concept not previously considered, namely mental toughness.

\section{Implicit Theories of Personal Attributes}

Implicit theories (Dweck \& Leggett, 1988), otherwise termed mindsets (Dweck, 2006), refer to the lay beliefs people hold about specific human attributes such as intelligence, personality, and athletic ability, with a particular focus on whether these qualities are considered immutable or changeable. A central premise of the implicit theory framework is that individuals differ with regard to their lay beliefs about the nature of human attributes, and these differences have important implications for behavior, performance, and well-being. Individuals who endorse an entity theory, or a fixed mindset, view qualities such as intelligence or personality as stable and trait-like whose opportunities for change or development are not within one's control, whereas people who endorse an incremental theory, or a growth mindset, view personal attributes as malleable and open to development 
or change (Dweck, 2006; Dweck \& Leggett, 1988). According to Dweck (2012), those individuals "who hold an incremental theory do not necessarily believe that everyone starts out with the same talent or potential, or that anyone can be anything...[rather] everyone has the ability to grow with the proper motivation, opportunity, and instruction" (p. 47).

Aligned with theoretical expectations, a significant body of research has supported the usefulness of people's implicit theories for understanding a variety of processes related to performance, behavior and well-being (for reviews, see Carr, Rattan, \& Dweck, 2012; Dweck, 2012). First, entity theorists are typically motivated towards demonstrating their competence or avoiding any displays of incompetence, whereas incremental theorists strive towards developing their competence or mastery of a task (Dweck \& Leggett, 1988; Mangels, Butterfield, Lamb, Good, \& Dweck, 2006). A second difference between the two types of implicit theories lies in effort beliefs. For entity theorists, effort has negative implications for ability, because they believe that if one has talent then effort or hard work is not required; in contrast, incremental theorists believe that effort is an essential part of growth and development, and is fundamental for translating ability into success (Blackwell, Trzesniewski, \& Dweck, 2007; Dweck \& Leggett, 1988). Third, implicit theories help shape one's interpretations of and reactions to the environment. For example, entity theorists tend to be less resilient than incremental theorists when confronted with setbacks, because they interpret the situation or event as implying a lack of ability and become discouraged or defensive (Blackwell et al., 2007; Hong, Chiu, Dweck, Lin, \& Wan, 1999). Collectively, this body of research has supported the adaptive nature of subscribing to an incremental theory, whereas holding an entity theory is typically maladaptive in nature.

\section{Mental Toughness: A Brief Overview}

The scientific study of mental toughness has occurred primarily within sport contexts (for reviews, see Gucciardi \& Gordon, 2011), and developed largely as a result of mental 
toughness being one of the most commonly applied but least understood terms used by individuals such as coaches and athletes (Jones, Hanton, \& Connaughton, 2002). Alongside the prevalence of mental toughness in the vernacular of these individuals, the increased scholarly attention to this concept in sport coincided with the rise of positive psychology in which the focus of both research and practice shifted from human malfunctioning toward that which also considers human strengths and optimal functioning (for reviews, see Lopez \& Snyder, 2009). As a personal resource considered important for both overcoming adversity as well as maintaining high levels of performance or functioning (e.g., Gucciardi, Hanton, Gordon, Mallett, \& Temby, in press; Jones, Hanton, \& Connaughton, 2007), mental toughness represents a contemporary application of the science of positive psychology in sport contexts (Rusk \& Waters, 2013). Conceptualized as one of the most important individual difference concepts for attaining and sustaining performance excellence across a variety of achievement contexts (e.g., sport, business, workplace), it is of no surprise that mental toughness has subsequently become an important focus in areas such as surgery (e.g., Colbert, Scott, Dale, \& Brennan, 2012), business (e.g., Jones \& Moorhouse, 2007), and law enforcement (e.g., Miller, 2008).

Although there is agreement among scholars that mental toughness represents a personal resource or individual difference variable which is central for performance despite stress or adversity (Hardy, Bell, \& Beattie, 2014), debate still exists as to the core attributes that characterize this concept. We do not intend to address this substantive concern in this paper; interested readers are referred elsewhere for such discussions (e.g., Gucciardi \& Gordon, 2011). Rather, what makes mental toughness a pertinent concept for the purposes of the current study is the recurring theme - whether it derives from scholars, practitioners, or the general public - that centers on whether individuals are born versus made mentally tough (e.g., Crust, 2007). Recognizing that life experiences (i.e., nurture) alongside biological 
factors (i.e., nature) are necessary to help shape one's development (Gottesman \& Hanson, 2005), researchers have attempted to better understand these developmental processes and mechanisms for mental toughness via retrospective interviews with elite performers or support staff (e.g., coaches, sport psychologists) who have worked with these individuals (for a review, see Connaughton, Thelwell, \& Hanton, 2011). In this research, however, an unintentional sampling bias may have existed whereby only those people who considered mental toughness to be malleable agreed to participate in the research. Thus, a substantively important yet untested assumption is whether the dominant viewpoint is that mental toughness is open to development and change. An implicit theory framework (Dweck \& Leggett, 1988) provided the theoretical backdrop upon which to examine this question.

\section{The Present Study}

In this study, we sought to integrate these two independent bodies of research for the first time by examining relations between implicit theories of mental toughness and cognitive, motivational and behavioral correlates considered hallmarks of this psychological concept across three different achievement contexts, namely education, sport, and the workplace. Theoretically, the model of implicit theories of personal attributes was conceptualized to suggest that these two beliefs foster different processes and outcomes pertinent to human behavior (e.g., goals, interpretation of and reactions to events) (Dweck \& Leggett, 1988). In an attempt to examine this assumption, we focused on a relatively broad set of key correlates to ascertain if these theoretical expectations were consistent across a variety of different processes and outcomes.

We first implemented a person-centered approach to identify subgroups of people who share similar implicit theories of mental toughness and differ from other subgroups of people (Von Eye \& Bogat, 2006). This approach seems especially important for verifying one of Dweck's $(2006,2012)$ key theoretical expectations about the study of implicit theories; 
that is, typically, approximately $40 \%$ of people endorse an incremental theory, $40 \%$ endorse an entity theory, and the remaining $20 \%$ are ambivalent (i.e., do not consistently endorse either theory $)^{2}$. The identification of implicit theory profiles amongst participants may reveal important information for both theory development (e.g., do different profiles exist, and how do they differ?) and applied practice (e.g., what is the prevalent mindset amongst individuals from various achievement contexts?). As this study is among the first to examine profiles of implicit theories, we based our hypothesis on theoretical expectations (Dweck, 2006, 2012). Thus, we expected to reveal support for three different profiles of implicit theories, that is, an entity theory cluster (i.e., high scores on entity, low scores on incremental), an incremental theory cluster (i.e., high scores on incremental, low scores on entity), and an ambivalent cluster (i.e., moderate scores on both theories).

Alongside the examination of implicit theory profiles, it is of substantive importance to ascertain their external validity using variables that were not used in the clustering process (Aldenderfer \& Blashfield, 1984). In other words, do profiles of implicit theories of mental toughness differ with regard to theoretically meaningful variables? Our selection of external validity variables was driven by the desire to cover a sufficiently broad assessment of cognitive, motivational, and behavioral correlates across three different achievement contexts. First, we assessed the relations between implicit theories of mental toughness with fear of failure and perceived stress among a sample of undergraduate students. Fear of failure refers to a dispositional tendency to avoid situations in which negative outcomes are possible due to a real or perceived risk of feeling ashamed from failure (Elliot \& Thrash, 2004) and has been related with mentally tough behavior (Gucciardi, Jackson, Hanton, \& Reid, in press). Because those people who endorse an entity theory are typically motivated to avoid displays of incompetence (Dweck \& Leggett, 1988; Mangels et al., 2006), we expected individuals who preferred an entity theory to report higher levels of fear of failure than 
people who subscribe to an incremental theory. Within the context of a transactional perspective (Lazarus \& Folkman, 1984), stress is considered to occur when individuals perceive events or situations in their environment to be taxing or exceeding their resources. Stress is central to conceptualizations of mental toughness and has been related with this psychological concept in athlete, student and employee samples (Gucciardi, Hanton, et al., in press; Hardy et al., 2014). Because entity theorists are disrupted by challenging situations (Mueler \& Dweck, 1998) and are less likely to engage in challenge seeking (Hong et al., 1999), we expected them to report higher levels of perceived stress than people who subscribe to an incremental theory.

Given the centrality of behavior or performance for conceptualizations of mental toughness (Gucciardi et al., in press; Hardy et al., 2014), we considered it important to examine indicators of behavior for the external validity of implicit theories of this personal attribute so as to align with the existing body of evidence (e.g., Burnette et al., 2013; Yeager et al., 2013) and theoretical expectations (Dweck \& Leggett, 1988). Job performance, as conceptualized and operationalized in the current study, refers to core-job tasks that are expected and necessary to fulfill the requirements of an assigned work role in an organization (Williams \& Anderson, 1991). The negative implications of an entity theory for performance have been established (Cury, Da Fonseca, Zahn, \& Elliot, 2008), therefore, we expected job performance to be higher in people who subscribe to an incremental theory when compared with an entity theory. Within an organizational context, creativity refers to employees' generation of novel and useful ideas concerning products, procedures, and processes at work (Amabile, 1988). Because creativity is positively associated with a learning goal orientation (Hirst, van Knippenberg, \& Zhou, 2009) and individuals' proactive explorations for evaluative information about their performance or feedback seeking (De Stobbeleir, Ashford, \& Buyens, 2009), we expected employees who subscribe to an incremental theory to display 
higher levels of creativity than people with a preference towards the belief that mental toughness is fixed or immutable.

Finally, we considered two key features of mental toughness conceptualizations resilience and thriving (Gucciardi et al, in press) - in a sample of adolescent athletes. Although there remains debate regarding a formal definition of resilience, common themes among most contemporary conceptualizations reveal that resilience encapsulates a dynamic process whereby one regains or sustains relatively stable, healthy levels of psychological and physical functioning, or experiences positive adaptation following exposure to significant adversity (Masten, 2011). In the current study, we operationalized resilience as the capacity to bounce back or recover from such major adversities or challenges, which is consistent with the original and basic meaning of the word ${ }^{3}$ (i.e., "spring back into shape" and "recover or adjust"). Entity theorists interpret setbacks or failures as an indication that they lack ability and become discouraged, whereas incremental theorists see these experiences as learning opportunities (Blackwell et al., 2007; Hong et al., 1999). Incremental theories, in particular, are associated with more adaptive responses to mistakes such as conscious attention to mistakes or errors (i.e., self-monitoring system; Moser, Schroder, Heeter, Moran, \& Lee, 2011). We expected individuals who subscribe to an incremental theory to report higher levels of resilience than people with a preference towards the belief that mental toughness is fixed or immutable. Thriving is defined as "the psychological state in which individuals experience both a sense of vitality and a sense of learning" (Spreitzer, Sutcliffe, Dutton, Grant, \& Sonenshein, 2005, p. 538). As an internal marker of individual growth and upward trajectory (Spreitzer \& Porath, in press), we expected individuals with an incremental theory of mental toughness to report higher levels of thriving than people who subscribe to an entity theory because of their orientation towards learning goals (Dweck \& Leggett, 1988; Mangels et al., 2006). 
In summary, the current study drew from an implicit theories of human attributes framework in an attempt to better understand perspectives on the malleability of mental toughness, and examine whether these personal beliefs are differentially associated with cognitive, motivational and behavioral correlates considered hallmarks of this psychological concept. We examined these research aims across three different samples in an attempt to ascertain whether or not implicit theories of mental toughness matter in more than one context. Specifically, students, employees, and athletes were chosen to capture key developmental periods including adolescence, early adulthood, and adulthood as well as achievement contexts which cover a variety of different pressures, challenges, and adversities that individuals must successfully negotiate.

\section{Methods}

Approval for this study was granted by the human ethics committee of a major Australian tertiary institution before data collection commenced. Prior to completing the survey, all participants were assured of confidentiality and anonymity in responses, and informed of their right to withdraw participation at any time before obtaining their consent.

\section{Undergraduate Sample}

Participants and procedure. A total of 451 undergraduates aged 17 to 26 years $(M=$ $19.25, S D=1.58)$ participated in this study. There were 114 males and 330 female students (seven students did not report their gender); all respondents were enrolled in first year undergraduate courses in psychology at a major Australian university and were offered course credit for their participation. Invitations were distributed via an established research participation scheme and included an overview of the study and a secure web address. Students completed an online survey containing measures of implicit theories of mental toughness, fear of failure, and perceived stress. 
Implicit theories of mental toughness. Drawing from Dweck's (1999) measurement of implicit theories of intelligence, we developed two 3-item subscales designed to assess incremental and entity theories of mental toughness (see Table 1). Items were rated on a scale from 1 (strongly disagree) to 7 (strongly agree) and scored such that higher numbers represented a stronger orientation toward incremental or entity beliefs. We adopted a 7-point Likert scale for both empirical (i.e., optimize reliability, validity, respondent preferences; Preston \& Colman, 2000) and conceptual reasons (i.e., the expectation that some people do not endorse either theory; Dweck, 2006, 2012). We averaged responses to create a mean score for entity and incremental theories. Cronbach's alpha supported the internal reliability of both entity (students $=.87$, employees $=.88$, athletes $=.82$ ) and incremental theories (students $=.92$, employees $=.91$, athletes $=.80)$ across all three samples.

Fear of failure. We employed a 5-item scale to capture participants' perceived degree of fear regarding failure in their academic pursuits (e.g., "When I am failing, it upsets my "plan" for the future") (Conroy, Willow, \& Metzler, 2002). Items were rated on a 5-point scale ranging from 1 (never believe) to 5 (always believe). We averaged responses to create a mean score for fear of failure $(\alpha=.80)$.

Perceived stress. The 10-item version of the perceived stress scale (Cohen, Kamarck, \& Mermelstein, 1983) was employed to assess the degree to which individuals' viewed situations in their life over the past month as stressful (e.g., "In the last month, how often have you felt that you were unable to control the important things in your life"). Items were rated on a 5-point scale ranging from 0 (Never) to 4 (Very Often). We averaged responses to create a mean score for perceived stress $(\alpha=.86)$.

\section{Employee Sample}

Participants and procedure. A total of 395 employees aged 25 to 79 years $(M=$ 48.78, $S D=9.27$ ) participated in this study. There were 209 males and 184 female employees 
(two employees did not report their gender). An email invitation including an information sheet and secure web address was distributed to employees via personal contacts of the researchers. Employees were "white collar" workers drawn from different organizations and diverse ranks of the Australian services sector such as education, health care and finance. Employees completed an online survey containing measures of implicit theories. After employees completed the measure of implicit theories of mental toughness, they provided their supervisor with a web address and a unique code. The supervisor subsequently rated the employee's in-role job performance and creativity.

Implicit theories of mental toughness. See student sample.

Performance. Each employee's workplace performance over the last month was assessed by his or her supervisor using a 7-item scale of in-role behaviors that are part of the formal job description (Williams \& Anderson, 1991). Sample items are "adequately complete assigned duties" and "neglect aspects of the job s/he is obligated to perform". The supervisor rated the extent to which each of the 7 behaviors was characteristic of the employee using a scale ranging from 1 (not at all) to 7 (to a great extent). We averaged responses to the 7 items to create a mean score for performance $(\alpha=.75)$.

Creativity. Each employee's creativity was assessed by his or her supervisor using a 13-item scale of behaviors associated with creative performance in the workplace (Zhou \& George, 2001). Sample items are "This employee is a good source of creative ideas" and “This employee often has a fresh approach to a problem". The supervisor rated the extent to which each of the 13 behaviors was characteristics of the employee using a scale ranging from 1 (not at all) to 7 (to a great extent). We averaged responses to the 13 items to create a mean score for creativity $(\alpha=.94)$.

\section{Athlete Sample}


Participants and procedure. A total of 230 female, adolescent netballers aged 11 to 17 years $(M=14.98 ; S D=1.51)$ participated in this study. The athlete data collection was conducted in collaboration with Netball Australia. Netball Australia's Athlete Identification and Development Manager assisted with the dissemination of the survey package. Netball Australia informed the netball community about the study and survey distribution process via email correspondence to key state and territory contacts and an e-newsletter tailored for coaches, parents, and players. Packages including an information sheet, consent forms (both parent and player), multisection survey (implicit theories of mental toughness, resilience, thriving), and a reply-paid envelope were provided to Netball Australia. These packages were subsequently distributed to players and their parents via coaches and key state and territory contacts. Players completed the survey package in their own time and sealed their responses in the reply-paid envelope. Completed surveys were returned directly to the research team via postal services or indirectly via Netball Australia.

Implicit theories of mental toughness. See student sample.

Resilience. Each netballer's perceived capacity to bounce back or recover from more serious stressful events was assessed using a 6-item resilience scale (Smith et al., 2008). The resilience scale contains three positively worded items (e.g., "It does not take me long to recover from a stressful event") and three negatively worded items (e.g., "It is hard for me to snap back when something bad happens"). Items were rated on a scale from 1 (strongly disagree) to 5 (strongly agree). Negatively worded items were reversed scored prior to scoring. We averaged responses to the 6 items to create a mean score for resilience $(\alpha=.71)$.

Thriving. Each netballer's perceived experiences of a psychological state composed of the joint experience of vitality and learning in netball was assessed using a 10-item measure (Porath, Spreitzer, Gibson, \& Garnett, 2012). This scale has two 5-item subscales designed to assess learning (e.g., "I continue to learn more and more as time goes by") and 
vitality (e.g., "I feel alive and vital"). Items were rated on a scale from 1 (strongly disagree) to 5 (strongly agree). We averaged responses to create a mean score for vitality $(\alpha=.76)$ and learning $(\alpha=.82)$.

\section{Results}

\section{Preliminary Analyses}

Data from all three samples were initially screened for missing cases, violations of assumptions of normality, and outliers. As less than $1 \%$ of values of the total dataset were not recorded by participants, missing values were replaced using the expectation-maximization method (Graham, 2009). Data screening revealed no violations against assumptions regarding univariate normality (i.e., $z$ score $> \pm 3.29$ ), multivariate outliers (i.e., using a $p<.001$ criterion for Mahalanobis $D^{2}$ ), skewness (i.e., $\left.<3\right)$, and kurtosis $(<10)$ for survey items and subscales (Hair, Black, Babin, \& Anderson, 2010).

\section{Profiles of Implicit Theories of Mental Toughness}

Cluster analyses were performed to classify participants into groups of similar patterns of scores across the two implicit theories of mental toughness. Standardized $z$-scores of the two implicit theory subscales were employed in the cluster analyses (Hair et al., 2010). We first performed a hierarchical cluster analysis with Ward's method and squared Euclidean distance as the similarity measure to identify clusters that minimize within-group variability and maximize between-group variability (Aldenderfer \& Blashfield, 1984). The results of the hierarchical method were then used as seeds for an optimization partitioning method $(k-$ means) also with squared Euclidean distance. Three solutions involving two, three or four clusters were identified as candidates for the $k$-means analysis according to the agglomeration coefficients and dendograms. The two cluster solution was deemed the best fit according to empirical (e.g., variance explained) and substantive criteria (e.g., minor differences in implicit theory scores between two clusters in both the three and four profile solutions). 
Stability analyses of the two-cluster solution revealed that most students (96\%), employees $(93 \%)$, and athletes $(92 \%)$ retained their original cluster membership across Ward's and $k$ means methods. Approximately $98 \%, 97 \%$ and $100 \%$ of the students, employees and athletes, respectively, were correctly classified using a discriminant function analysis.

Following the identification of the optimal number of clusters, a multivariate analysis of variance (MANOVA) was performed to examine mean levels of each type of implicit theory across the two clusters in each sample. There was a significant multivariate effect of cluster membership on the two implicit theory subscales in the students, Wilks $\Lambda=.32, F(2$, $448)=481.98, p<.001, \eta_{\mathrm{P}}^{2}=.68$, employees, Wilks $\Lambda=.29, F(2,392)=483.93 p<.001, \eta_{\mathrm{P}}^{2}$ $=.71$, and netballers, Wilks $\Lambda=.27, F(2,227)=301.96, p<.001, \eta_{\mathrm{P}}^{2}=.73$. Both relative (i.e., standardized $z$-scores) and absolute (i.e., raw scores) scores were examined to aid in the interpretation of the two-cluster solution (see Table 2). Typically, a standardized $z$-score of \pm .50 is considered reflective of high and low levels of a subscale, respectively, with scores in between $(.50$ to -.50$)$ consistent with moderate levels (e.g., Harwood, Cumming, \& Fletcher, 2004). Both relative and absolute scores indicated that the first cluster reported high levels of an incremental theory in conjunction with low levels of an entity theory. Aligned with Dweck's $(2006,2012)$ categorization of different types of implicit theories, this cluster was labelled as an incremental theory. For Cluster 2, relative scores indicated that participants reported high levels of an entity theory alongside low levels of an incremental theory, whereas absolute scores suggested moderate levels of both implicit theories. As relative scores are subject to characteristics of specific samples, we decided to label this cluster as an ambivalent theory.

\section{External Validity of the Implicit Theory Profiles}

The two-cluster implicit theory profile was subsequently employed to examine differences on the key external validity correlates in each of the three samples (see Table 2). 
The multivariate combination of fear of failure and perceived stress was significantly different between the two clusters in the students, Wilks $\Lambda=.96, F(2,448)=9.67, p<.001$, $\eta_{\mathrm{P}}^{2}=.04$. When compared with the ambivalent theory cluster, the post hoc ANOVA with Scheffe's test for comparison of means revealed that the incremental theory cluster reported lower levels of fear of failure and perceived stress. With regard to the employees, a MANOVA revealed a significant multivariate effect of cluster membership on the combination of job performance and creativity, Wilks $\Lambda=.95, F(2,392)=10.01, p<.001$, $\eta_{\mathrm{P}}^{2}=.05$. The post hoc ANOVA with Scheffe's test for comparison of means revealed that the incremental theory cluster were rated by their supervisor as being significantly higher on job performance and creativity than the ambivalent theory cluster. Finally, the multivariate combination of combination of resilience and thriving was significantly different between the two clusters in the netballers, Wilks $\Lambda=.86, F(3,226)=11.91, p<.001, \eta_{\mathrm{P}}^{2}=.14$. The post hoc ANOVA with Scheffe's test for comparison of means revealed that the incremental theory cluster reported significantly higher levels of resilience, learning and vitality than the ambivalent theory cluster. Cohen's (1988) guidelines can be used for the interpretation of effect sizes (Cohen's $d$ ) reported in Table 2; low (.20), moderate (.50) and large (.80).

\section{Discussion}

The primary aim of this study was to test whether an incremental theory of mental toughness (i.e., it is malleable and open to development) was the predominant belief system for performers across three different achievement contexts; our results revealed that this perspective might not be the case. Specifically, we identified different profiles or combinations of implicit theories of mental toughness in which people were characterized by an incremental or ambivalent theory. Subsequent analyses revealed that these clusters differed on cognitive, motivational, and behavioral correlates consistent with theoretical expectations. 
Based on two decades of research on implicit theories, Dweck $(2006,2012)$ noted that, on average, approximately $40 \%$ of people endorse an incremental theory, $40 \%$ endorse an entity theory, and the remaining $20 \%$ are ambivalent (i.e., do not consistently endorse either theory). Although not explicitly detailed in her writings on this issue, this kind of conclusion suggests that different types or profiles of implicit theories of human attributes exist. To the best of our knowledge, this theoretical contention had yet to be empirically tested. Our findings provided support for the theoretical prediction that people could be classified into meaningful and homogenous groups based on their implicit theories of mental toughness. However, our expectation that a tripartite typology of implicit profiles would emerge in our samples was not supported. Contrary to Dweck's estimations, we revealed support for a bipartite typology of implicit theories of mental toughness which encompassed clusters of incremental theorists and an ambivalent group, but not a profile of entity theorists. The number of people in each cluster was evenly distributed for both the athletes and students, whereas there was a higher proportion of employees in the incremental theory cluster (64\%) when compared with the ambivalent theory group (36\%). These findings suggest that people either believe mental toughness is open to change and development, or are ambivalent as to its malleability. As mental toughness is considered a complex, multidimensional concept (Connaughton et al., 2011), it may be that people in the ambivalent cluster believe some aspects of mental toughness are malleable whereas other components are immutable. It could also be that individuals believe that some people may be more likely to change or develop (e.g., high socio-economic status and therefore access to numerous resources) when compared with other individuals (e.g., low socio-economic status and therefore little access to resources).

An unexpected finding was that evidence for a predominant entity theory cluster (i.e., high entity theory, low incremental theory) was not obtained. This aspect of our results 
differs from Dweck's $(2006,2012)$ estimations regarding the prevalence of different types of implicit theories among the population. Cultural differences between samples may provide an explanation for the unexpected finding. Specifically, Dweck has conducted much of her research in North America, whereas we sampled our participants from Australia. Another explanation for the non-existence of a predominant entity theory cluster may have to do with the specific concept in question, such that intelligence might be viewed by some as more resistant to change than mental toughness; in other words, mental toughness is a concept that most people believe is, to some degree at least, malleable and open to development. It may also be possible that participants had read a definition (e.g., undergraduate studies in psychology) or heard someone (e.g., elite athlete) describe mental toughness as being malleable or open to development prior to their participation in the study. These explanations are speculative and require testing in future research. Nevertheless, from a practical perspective, it is encouraging that few people subscribed to a predominant entity theory perspective, given that this belief type is typically associated with maladaptive processes and outcomes (Burnette et al., 2013; Carr et al., 2012; Yeager et al., 2013).

External validity analyses of implicit theory clusters of mental toughness were consistent with expectations. Across all three samples, people in the incremental theory cluster reported more adaptive responses on the cognitive, motivational, and behavioral variables than the ambivalent theory cluster. These findings contribute to an impressive body of research which has supported the adaptive nature of an incremental theory (Burnette et al., 2013; Carr et al., 2012; Yeager et al., 2013). However, although these differences between the two implicit theory clusters were statistically significant, an inspection of both the raw and standardized scores alongside the effect sizes suggests that these differences were small. Although speculative, it may be that larger differences might have emerged between a predominant incremental theory profile and a true entity theory cluster. In other words, 
subscribing to the viewpoint that that mental toughness is to some degree both malleable and immutable, as is the case with ambivalent cluster, may be less maladaptive than believing purely that it is immutable. Another explanation for the small differences in the external validity variables between the incremental theory cluster and ambivalent theory group may lie in the focus of our measurement of implicit theories. We assessed individuals' general beliefs about the malleability of mental toughness; these beliefs may differ from people's perception of their confidence in their ability to change or enhance their own mental toughness. For example, people may believe that mental toughness is malleable but lack confidence in their own ability to bring about change for their own personal development.

The results of this study also offer important implications for the scientific study of mental toughness. The issue of whether mental toughness is immutable or changeable has divided scholars; some believe that mental toughness is a relatively stable dispositional trait (e.g., Hardy et al., 2014), whereas others have suggested (e.g., Harmison, 2011) or found (e.g., Gucciardi et al., in press) it is state-like and open to change or development. Explorations of individuals' perceptions regarding mental toughness development support an incremental theory perspective (Connaughton et al., 2011), though it has been assumed that these individuals believe mental toughness can be developed or changed, or people who consider mental toughness to be malleable are purposefully sampled to provide their views. Nevertheless, there is preliminary evidence to support the effectiveness of interventions designed to enhance mental toughness among adolescent athletes (Bell, Hardy, \& Beattie, 2013; Gucciardi, Gordon, \& Dimmock, 2009). The current study, therefore, makes two important contributions to the issue of mental toughness. First, we showed that it might be erroneous to assume that all people subscribe to the viewpoint that mental toughness is (entirely) open to development. Furthermore, people's lay beliefs about the malleability of mental toughness have important implications for cognitive (e.g., thoughts about one's 
available resources to deal with situational demands), motivational (e.g., avoidance or approach), and behavioral variables (e.g., performance) that have been reported as important correlates in previous research (e.g., Connaughton et al., 2011). Second, our study is among the first to examine issues related to peoples' perceptions of the malleability of mental toughness in non-athlete samples thereby alleviating limitations associated with a somewhat narrow sampling strategy in previous research. By exploring these issues across three achievement contexts, our results provided preliminary evidence to support the notion that implicit theories of mental toughness matter for performers in different achievement contexts.

Our broad sampling strategy, which included moderately large datasets from multiple achievement contexts and participants across key developmental periods including adolescence, early adulthood, and adulthood, was the key strength of this study. Thus, we provided an initial insight into how well these findings generalize across achievement contexts and samples. Nevertheless, the results of this study must be interpreted in light of the limitations of our research. First, with the exception of supervisor ratings of in-role job performance and creativity for the workplace sample, the common method between study variables may have biased estimates (e.g., means, variances) thereby leading to erroneous conclusions (for a review, see Podsakoff, MacKenzie, \& Podsakoff, 2012). Both procedural (e.g., using different sources and/or temporal separation to assess study variables) and statistical remedies (e.g., confirmatory factor analysis marker technique) can help alleviate such concerns in future research. Another limitation is the cross-sectional nature of our design. Experimental manipulations of implicit theories are required to make inferences about causality, whereas longitudinal designs have the potential to offer insights into the in/stability of people's implicit theories of personal attributes. Finally, we did not provide participants with a description of mental toughness in the information sheet or survey instructions. Although this approach is consistent with previous research on implicit theories, we cannot 
rule out the potential influence of differences in the way in which mental toughness is personally defined via responses on implicit theories of this personal attribute.

Our study offered several important contributions to the study of both implicit theories and mental toughness. We showed that not all people subscribe to the viewpoint that mental toughness is open to development or change. Our findings also revealed that different types of implicit theory clusters exist, though not totally consistent with Dweck's (2006, 2012) proposed tripartite conceptualization. An understanding of implicit theory clusters is important because it underscores the role of entity and incremental theories considered jointly rather than in isolation. It is our hope that these initial findings will stimulate additional research that seeks to replicate and extend our work (e.g., longitudinal stability of implicit theory profiles). 


\section{Footnotes}

${ }^{1}$ Though, an explanation which encompasses an interaction of multiple systems may be equally justified (e.g., Gottesman \& Hanson, 2005). Indeed, "it is perfectly possible for an individual to hold both theories" (Dweck, Chiu, \& Hong, 1995b, p. 323).

${ }^{2}$ This estimate is based largely on Dweck's research on intelligence and personality with samples from North America. Participants dis/agreement with statements designed to capture implicit theories of personal attributes are typically reported using a 6-point Likert scale from 1 (strongly agree) to 6 (strongly disagree). Respondents who score an average of 3 or below are classified as entity theorists; those individuals who score an average of 4 or above are designed as incremental theorists. These criteria typically result in $85 \%$ of people being classified in either of the groups, with the remaining $15 \%$ excluded from subsequent analyses because "they do not represent extreme groups" (Dweck, Chiu, \& Hong, 1995a, p. 269).

\footnotetext{
${ }^{3}$ We consulted both the Merriam-Webster and Oxford English online dictionaries.
} 


\section{References}

Aldenderfer, M. S., \& Blashfield, R. K. (1984). Cluster analysis. Newbury Park, CA: Sage. Amabile, T. M. (1988). A model of creativity and innovation in organizations. In B. M. Staw \& L. L. Cummings (Eds.), Research in organizational behavior, (Vol. 10, pp. 123167). Greenwich, CT: JAI Press.

Bell, J. J., Hardy, L., \& Beattie, S. (2013). Enhancing mental toughness and performance under pressure in elite young cricketers: A 2-year longitudinal intervention. Sport, Exercise, and Performance Psychology, 2, 281-297. doi: 10.1037/a0033129

Blackwell, L. S., Trzesniewski, K. H., \& Dweck, C. S. (2007). Implicit theories of intelligence predict achievement across an adolescent transition: A longitudinal study and an intervention. Child Development, 78, 246-263. doi: 10.1111/j.14678624.2007.00995.x

Burnette, J. L., O’Boyle, E. H., VanEpps, E. M., Pollack, J. M., \& Finkel, E. J. (2013). Mindsets matter: A meta-analytic review of implicit theories and self-regulation. Psychological Bulletin, 139, 655-701. doi: 10.1037/a0029531

Carr, P., Rattan, A., \& Dweck, C. S. (2012). Implicit theories shape intergroup relations. Advances in Experimental Social Psychology, 45, 127-165. doi: 10.1016/B978-0-12394286-9.00003-2

Cohen, J. (1988). Statistical power analysis for the behavioral sciences $\left(2^{\text {nd }}\right.$ ed.). Hillsdale, NJ: Erlbaum.

Cohen, S., Kamarck, T., \& Mermelstein, R. (1983). A global measure of perceived stress. Journal of Health and Social Behavior, 24, 385-396. doi:10.2307/2136404

Colbert, S. D., Scott, J., Dale, T., \& Brennan, P. A. (2012). Performing to a world class standard under pressure - Can we learn lessons from the Olympians? British Journal of Oral and Maxillofacial Surgery, 50, 291-297. doi: 10.1016/j.bjoms.2012.04.263 
Connaughton, D., Thelwell, R., \& Hanton, S. (2011). Mental toughness development: Issues, practical implications and future directions. In D. F. Gucciardi \& S. Gordon (Eds.), Mental toughness in sport: Developments in research and theory (pp. 136-162). Abingdon, Oxon: Routledge.

Conroy, D. E., Willow, J. P., \& Metzler, J. N. (2002). Multidimensional fear of failure measurement: The performance failure appraisal inventory. Journal of Applied Sport Psychology, 14, 76-90. doi: 10.1080/10413200252907752

Crust, L. (2007). Mental toughness in sport: A review. International Journal of Sport and Exercise Psychology, 5, 270-290. doi: 10.1080/1612197X.2007.9671836

Cury, F., Da Fonseca, D., Zahn, I., \& Elliot, A. (2008). Implicit theories and IQ test performance: A sequential mediational analysis. Journal of Experimental Social Psychology, 44, 783-791. doi:10.1016/j.jesp.2007.07.003

De Stobbeleir, K. E. M., Ashford, S. J., \& Buyens, D. (2011). Self-regulation of creativity at work: The role of feedback-seeking behavior in creative performance. Academy of Management Journal, 54, 811-831. doi: 10.5465/AMJ.2011.6487014d

Dweck, C. S. (2006). Mindset: The new psychology of success. New York, NY: Ballantine Books.

Dweck, C. S. (2012). Implicit theories. In P. A. M. Van Lange, A. W. Kruglanski, \& E. T. Higgins (Eds.). Handbook of theories in social psychology (Vol. 2, pp. 43-62). Thousand Oaks, CA: Sage Publications.

Dweck, C. S., Chiu, C-Y., \& Hong, Y-Y. (1995a). Implicit theories and their role in judgments and reactions: A world from two perspectives. Psychological Inquiry, 6, 267-285. doi: 10.1207/s15327965pli0604_1 
Dweck, C. S., Chiu, C-Y., \& Hong, Y-Y. (1995b). Implicit theories: Elaboration and extension of the model. Psychological Inquiry, 6, 322-333. doi:

10.1207/s15327965pli0604_12

Dweck, C. S., \& Leggett, E. L. (1988). A social-cognitive approach to motivation and personality. Psychological Review, 95, 256-273. doi:10.1037//0033-295X.95.2.256

Elliot, A. J., \& Thrash, T. M. (2004). The intergenerational transmission of fear of failure. Personality and Social Psychology Bulletin, 30, 957-971. doi:

\section{$10.1177 / 0146167203262024$}

Gottesman, I. I., \& Hanson, D. R. (2005). Human development: Biological and genetic processes. Annual Review of Psychology, 56, 263-286. doi:

10.1146/annurev.psych.56.091103.070208

Graham, J. W. (2009). Missing data analysis: making it work in the real world. Annual Review of Psychology, 60, 549-576. doi: 10.1146/annurev.psych.58.110405.085530

Gucciardi, D. F., \& Gordon, S. (Eds.) (2011). Mental toughness in sport: Developments in research and theory. Abingdon, Oxon: Routledge.

Gucciardi, D.F., Gordon, S., \& Dimmock, J.A. (2009). Evaluation of a mental toughness training program for youth-aged Australian footballers: I. A quantitative analysis. Journal of Applied Sport Psychology, 21, 307-323. doi: 10.1080/10413200903026066

Gucciardi, D. F., Hanton, S., Gordon, S., Mallett, C. J., \& Temby, P. (in press). The concept of mental toughness: Tests of dimensionality, nomological network, and traitness. Journal of Personality. doi: 10.1111/jopy.12079

Gucciardi, D.F., Jackson, B., Hanton, S., \& Reid, M. (in press). Motivational correlates of mentally tough behavior. Journal of Science and Medicine in Sport. doi: 10.1016/j.jsams.2013.11.009 
Hair, J. F., Black, W. B., Babin, B. J., \& Anderson, R. E. (2010). Multivariate data analysis (7th ed.). Upper Saddle River, N.J: Prentice Hall.

Hardy, L., Bell, J., \& Beattie, S. (2014). A neuropsychological model of mentally tough behaviour. Journal of Personality, 82, 69-81. doi: 10.1111/jopy.12034

Harmison, R. J. (2011). A social-cognitive framework for understanding and developing mental toughness in sport. In D. F. Gucciardi \& S. Gordon (Eds.), Mental toughness in sport: Developments in research and theory (pp. 47-68). Abingdon, Oxon: Routledge.

Harwood, C., Cumming, J., \& Fletcher, D. (2004). Motivational profiles and psychological skills use within elite youth sport. Journal of Applied Sport Psychology, 16, 318-332. doi:_10.1080/10413200490517986

Hirst, G., van Knippenberg, D., \& Zhou, J. (2009). A cross-level perspective on employee creativity: Goal orientation, team learning behavior, and individual creativity. Academy of Management Journal, 52, 280-293. doi: 10.5465/AMJ.2009.37308035

Hong, Y. Y., Chiu, C., Dweck, C. S., Lin, D., \& Wan, W. (1999). Implicit theories, attributions, and coping: A meaning system approach. Journal of Personality and Social Psychology, 77, 588-599. doi:10.1037/0022-3514.77.3.588

Jones, G., Hanton, S., \& Connaughton, D. (2002). What is this thing called mental toughness? An investigation of elite sport performers. Journal of Applied Sport Psychology, 14, 205-218. doi:_10.1080/10413200290103509

Jones, G., Hanton, S., \& Connaughton, D. (2007). A framework of mental toughness in the world's best performers. The Sport Psychologist, 21, 243-264.

Jones, G., \& Moorehouse, A. (2007). Developing mental toughness: Gold medal strategies for transforming your business performance. Begbroke, Oxford: Spring Hill.

Lazarus, R. S., \& Folkman, S. (1984). Stress appraisal and coping. New York, NY: Springer. 
Lopez, S. J., Snyder, C. R. (Eds.) (2009). The Oxford handbook of positive psychology (2 ${ }^{\text {nd }}$ ed.). Oxford, UK: Oxford University Press.

Mangels, J. A., Butterfield, B., Lamb, J., Good, C., \& Dweck, C. S. (2006). Why do beliefs about intelligence influence learning success? A social cognitive neuroscience model. Social Cognitive and Affective Neuroscience, 1, 75-86. doi:10.1093/scan/ns1013

Masten, A. S. (2011). Resilience in children threatened by extreme adversity: Frameworks for research, practice, and translational synergy. Development and Psychopathology, 23, 493-506. doi:10.1017/S0954579411000198

Miller, L. (2008). Stress and resilience in law enforcement training and practice. International Journal of Emergency Mental Health, 10, 109-124.

Moser, J. S., Schroder, H. S., Heeter, C., Moran, T. P., \& Lee, Y-H. (2011). Mind your errors: Evidence for a neural mechanism linking growth mind-set to adaptive posterior adjustments. Psychological Science, 22, 1484-1489. doi: 10.1177/0956797611419520

Podsakoff, P. M., MacKenzie, S. B., \& Podsakoff, N. P. (2012). Sources of method bias in social science research and recommendations on how to control it. Annual Review of Psychology, 63, 539-569. doi: 10.1146/annurev-psych-120710-100452

Porath, C. L., Spreitzer, G., Gibson, C., \& Garnett, F. S. (2012). Thriving in the workplace: Towards its measurement, construct validation, and theoretical refinement. Journal of Organizational Behavior, 33, 250-275. doi: 10.1002/job.756

Preston, C. C., \& Colman, A. M. (2000). Optimal number of response categories in rating scales: Reliability, validity, discriminating power, and respondent preferences. Acta Psychologica, 104, 1-15. doi: 10.1016/S0001-6918(99)00050-5

Roberts, B. W., \& Mroczek, D. (2008). Personality trait change in adulthood. Current Directions in Psychological Science, 17, 31-35. doi: 10.1111/j.14678721.2008.00543.x 
Rusk, R. D., \& Waters, L. E. (2013). Tracing the size, reach, impact, and breadth of positive psychology. Journal of Positive Psychology, 8, 207-221. doi:

$10.1080 / 17439760.2013 .777766$

Smith, B. W., Dalen, J., Wiggins, K., Tooley, E., Christopher, P., \& Bernard, J. (2008). The Brief Resilience Scale: Assessing the ability to bounce back. International Journal of Behavioral Medicine, 15, 194-200. doi: 10.1080/10705500802222972

Spreitzer, G., \& Porath, C. (in press). Self-determination theory as a nutriment for thriving: Building an integrative model of human growth at work. In M. Gagné (Ed.), Oxford handbook of work engagement, motivation and self-determination theory. New York, NY: Oxford University Press.

Spreitzer, G., Sutcliffe, K., Dutton, J., Grant, A. M., \& Sonenshein, S. (2005). A socially embedded model of thriving at work. Organization Science, 16, 537-549. doi: 10.1287/orsc. 1050.0153

Von Eye, A., \& Bogat, G. A. (2006). Person-oriented and variable-oriented research: Concepts, results, and development. Merrill-Palmer Quarterly, 52, 390-420. doi: $10.1353 / \mathrm{mpq} .2006 .0032$

Williams, L. J., \& Anderson, S. E. (1991). Job satisfaction and organizational commitment as predictors of organizational citizenship and in-role behaviors. Journal of Management, 17, 601-617. doi: 10.1177/014920639101700305

Yeager, D. S., Miu, A. S., Powers, J., \& Dweck, C. S. (2013). Implicit theories of personality and attributions of hostile intent: A meta-analysis, an experiment, and a longitudinal intervention. Child Development, 84, 1651-1667. doi: 10.1111/cdev.12062

Zhou, J., \& George, J. M. (2001). When job dissatisfaction leads to creativity: Encouraging the expression of voice. Academy of Management Journal, 44, 682-696. doi: $10.2307 / 3069410$ 
Table 1. Item statistics for implicit theories of mental toughness.

\begin{tabular}{|c|c|c|c|c|c|c|c|c|c|c|c|c|}
\hline & \multicolumn{4}{|c|}{ Students $(n=451)$} & \multicolumn{4}{|c|}{ Employees $(n=395)$} & \multicolumn{4}{|c|}{ Athletes $(n=230)$} \\
\hline & $M$ & $S D$ & Skew & Kurtosis & $M$ & $S D$ & Skew & Kurtosis & $M$ & $S D$ & Skew & Kurtosis \\
\hline Item 1 & 3.69 & 1.64 & .06 & -.93 & 3.33 & 1.87 & .43 & -1.12 & 3.38 & 1.65 & .18 & -.89 \\
\hline Item 2 & 3.50 & 1.70 & .25 & -.98 & 3.04 & 1.78 & .71 & -.65 & 3.09 & 1.66 & .42 & -.75 \\
\hline Item 3 & 4.86 & 1.60 & -.51 & -.57 & 5.34 & 1.63 & -1.02 & .16 & 5.12 & 1.63 & -.64 & -.33 \\
\hline Item 4 & 3.04 & 1.69 & .56 & -.76 & 2.35 & 1.54 & 1.26 & .76 & 2.69 & 1.64 & .83 & -.17 \\
\hline Item 5 & 4.74 & 1.61 & -.37 & -.69 & 5.26 & 1.62 & -.87 & -.20 & 5.11 & 1.56 & -.60 & -.34 \\
\hline Item 6 & 4.86 & 1.58 & -.40 & -.74 & 5.36 & 1.65 & -1.00 & .06 & 5.32 & 1.43 & -.60 & -.36 \\
\hline
\end{tabular}

Note: Entity items are items 1 (You have a certain degree of mental toughness and you can't really do much to change it), item 2 (Your mental toughness is something about you that you can't really change that much), and item 4 (To be honest, you can't really change your mental toughness), and incremental items are item 3 (No matter who you are, you can significantly change your mental toughness), item 5 (You can always substantially change your mental toughness), and item 6 (You can change your mental toughness considerably). 
Table 2. Descriptive and summary ANOVA statistics by cluster group on implicit theories of mental toughness.

$$
\text { Incremental Theory Ambivalent Theory }
$$

Cluster Cluster

\begin{tabular}{llllll}
\hline$M(S D)$ & $z$ & & & & \\
\cline { 1 - 1 } &
\end{tabular}

\begin{tabular}{|c|c|c|c|c|c|c|}
\hline Students & \multicolumn{2}{|c|}{$(n=241)$} & \multicolumn{2}{|c|}{$(n=210)$} & \multirow[b]{2}{*}{$699.83 * *$} & \multirow[b]{2}{*}{$2.52(2.27,2.76)$} \\
\hline Entity theory & $2.32(.84)$ & -.72 & $4.67(1.03)$ & .84 & & \\
\hline Incremental theory & $5.78(.95)$ & .64 & $3.73(1.22)$ & -.74 & $399.09 * *$ & $1.88(1.66,2.10)$ \\
\hline Fear of failure & $3.09(.96)$ & -.09 & $3.29(.92)$ & .11 & $5.05 *$ & $.21(.03, .40)$ \\
\hline Perceived stress & $1.86(.66)$ & -.21 & $2.13(.64)$ & .19 & $19.30 * *$ & $.41(.23, .60)$ \\
\hline Employees & \multicolumn{2}{|c|}{$(n=253)$} & \multicolumn{2}{|c|}{$(n=142)$} & & \\
\hline Entity theory & $2.00(.83)$ & -1.03 & $3.77(1.25)$ & .58 & $603.72 * *$ & $1.77(1.52,2.00)$ \\
\hline Incremental theory & $6.19(.74)$ & 1.03 & $4.53(1.21)$ & -.58 & $579.97 * *$ & $1.77(1.52,2.01)$ \\
\hline Job performance & $6.23(.64)$ & .15 & $5.94(.78)$ & -.26 & $15.99 * *$ & $.42(.21, .62)$ \\
\hline Creativity & $6.09(.67)$ & .12 & $5.87(.71)$ & -.21 & $10.28 * *$ & $.32(.11, .53)$ \\
\hline Athletes & \multicolumn{2}{|c|}{$(n=111)$} & \multicolumn{2}{|c|}{$(n=119)$} & & \\
\hline Entity theory & $2.01(.78)$ & -.74 & $4.03(1.14)$ & .69 & $238.18 * *$ & $2.06(1.73,2.37)$ \\
\hline Incremental theory & $6.18(.73)$ & .76 & $4.26(1.00)$ & -.71 & $272.63 * *$ & $2.18(1.85,2.50)$ \\
\hline Resilience & $3.75(.61)$ & .22 & $3.49(.61)$ & -.20 & $10.84 * *$ & $.43(.16, .69)$ \\
\hline Learning & $6.32(.59)$ & .37 & $5.72(.92)$ & -.35 & $33.91 * *$ & $.77(.50,1.04)$ \\
\hline Vitality & $6.12(.72)$ & .27 & $5.66(.94)$ & -.25 & $17.21 * *$ & $.55(.28, .81)$ \\
\hline
\end{tabular}

Note: $* p<.05 ; * * p<.001 ; \mathrm{CI}=$ confidence intervals. 